\title{
Assessing the New Normal: Dangers Related to the Internet Use and Risks Facing Vulnerable Psychiatric Populations
}

\author{
J'Andra Antisdel ${ }^{1}$ \\ ${ }^{1}$ Visiting Clinical Assistant Professor, Indiana University South Bend, South Bend, Indiana, USA \\ Correspondence: Samuel P. Abraham, Associate Professor of Nursing, Bethel University, 1001 Bethel Circle, \\ Mishawaka, Indiana, USA
}

Received: May 12, 2019

Accepted: May 27, 2019

Online Published: May 29, 2019

doi:10.20849/ijsn.v4i2.584

URL: https://doi.org/10.20849/ijsn.v4i2.584

\begin{abstract}
Background: Despite the social and cultural changes surrounding the immergence of social media and the risks related to internet use for adolescents, mental health screenings have not changed to assess the psycho-social implications of social media and internet use in general as social support

Purpose: Mental health professionals who assess patient use of social media and internet will be informed of dangerous online support groups promoting negative coping behaviors and risk or occurrence of psychological, physical or sexual abuse arising from dangerous internet use.

Method: The following databases were searched: Academic Search Premier, CINAHL Plus with Full Text, Health Source: Nursing/Academic Edition, MEDLINE, PsycARTICLES, PsycINFO, and SocINDEX with Full Text, using a combination of search terms self-harm, and Internet with Boolean phrase and, and limiters including publication years between 2010-2018.

Conclusion: During the screening process, mental health professionals can begin to address this emergent concern by asking internet specific questions designed to inform the professional about patient risk concerning social media and internet use. It is important to continue to assess and evaluate screening methods to ensure mental health screenings are adapting to the changing technological world. Social media and internet use have changed the way humans communicate and form social connections. It is imperative mental health professionals assess the implications of dangerous social media and internet use concerning mental health.
\end{abstract}

Keywords: social media, dangerous internet use, online support groups, social media risks

\section{Introduction}

A few taps on the keyboard and a simple click of the mouse allows almost anyone to reach out and touch the lives of countless people all around the globe. Add to this any cheap webcam and one can broadcast themselves into any home, speaking face to face with near perfect clarity with a friend or loved one. The use of this technology has allowed communication to evolve in a multitude of beneficial ways, but unfortunately, unforeseen hazards and pitfalls lie in wait for those who may be ill equipped for the dangers of unlimited and unmoderated online communication.

According to the U.S. Digital Consumer Report, Americans are spending on average of 60 hours a week on social media (Nielsen Mobile Shopping Report, 2014). Patients experiencing mental health issues are going online to research or discuss their symptoms with others, often finding and forming new virtual social support groups. Researchers found some are more likely to discuss mental health symptoms online before they would disclose in person (Moreno et al., 2011, pp. 452-454). Despite this, attitudes among mental health professionals in the psychiatric acute area, specifically in the screening process for inpatient admission, have not changed. It is possible this can be alleviated by adding several questions to the screening related to internet use and risk factors for possible danger and or exposure to triggering content online.

Within the organization of change, a nurse or social worker will ask questions concerning social structures, support, suicide risk, and abuse, but often aspects of online social dynamics and internet use are often missed and the potential dangers these represent are unaccounted for, leaving patients at risk, particularly vulnerable adolescents. 


\subsection{Methodology}

The following databases were searched: Academic Search Premier, CINAHL Plus with Full Text, Health Source: Nursing/Academic Edition, MEDLINE, PsycARTICLES, PsycINFO, and SocINDEX with Full Text, using a combination of search terms self-harm, and Internet with Boolean phrase and, and limiters including publication years between 2010-2018. This database search initially yielded 447 results. A second search was initiated using the search terms social media and mental health with the Boolean phrase and, and the same publication year limiters. The reference list from a relevant systematic review yielded another article. After reviewing the abstracts articles were chosen based on relevancy to adolescent psycho-social health issues. Seven articles were then reviewed for this publication.

\section{Proposition for Change}

The desired change for a psychiatric facility in an urban Midwestern city would be to simply add several questions to a form within the electronic health record. The questions are related to internet activity and safety for purposes of assessing the nature of online social support symptoms and possible risk for abuse or harm to adolescent patients. A tool was developed listing the following questions:

How much time do you spend on the internet?

Have you shared your [suicidal] plan with anyone online?

Have you been triggered by anyone you've seen or met online?

How did you develop your plan? How did you come to that decision?

Has anyone ever suggested or encouraged you to hurt yourself?

Have you ever searched on the internet about the way you feel online?

Have photographs or other images been shared online without your consent?

Has anyone threatened to share photos or images without your consent?

Have you ever been told how to hurt yourself?

Has anyone online ever threatened to harm you or your family members?

Asking these questions will allow mental health professionals to further assess the safety of the adolescent. Insight would be gained concerning the use of dangerous online support groups promoting suicide or self-harm. These questions also allow for screening for potential psychological or sexual abuse which would legally have to be reported to the state Department of Child Services. For patients who are being harmed, asking these questions may lead to a relief from the weight of spiritual disturbance brought on by misappropriated guilt and shame (Dorahy \& Clearwater, 2012, pp. 171-172).

\section{Cultural Assessment}

Giger (2013) discusses the importance of assessing an individual's cultural background and how it relates to their care and interpretation of their own health needs. Different medical interventions exist for different ethnicities due to either biological or cultural characteristics of the ethnic group (p. 3). For example, the rare disorder Tay-Sachs disease is more common in people of Ashkenazi Jewish heritage. A family with this heritage and family history of Tay-Sachs may be counseled to have genetic testing prior to conceiving (U.S. National Library of Medicine, 2018). The same attention to cultural and ethnic differences must be apparent in mental health screenings as well. The Giger and Davidhizar Transcultural Assessment Model, a versatile tool used to assess for cultural differences in many disciplines, can also be used as a guideline for assessing patients for risk for harm online. Using Giger's description of the six-cultural phenomenon "communication, space, social organization, time, environmental control, and biological variations" (Giger, 2013, p. 5) the assessment can be adjusted for questions concerning internet safety. For example, questions asked to reveal insight concerning internet supervision, websites and social media used, time spent online and use of privacy and anonymity relate to the phenomenon of environmental control, time and space (Giger, 2013, pp. 3-7) Giger and Davidhizar's Transcultural Assessment Module is applicable to internet safety assessments.

\section{Nursing Diagnosis}

Increased risk for self-harm/self-mutilation as evidenced by frequently visiting self-harm promotion websites: On the internet, one can find information about any topic they wish; simply use any search engine and not only will one find text information, but images and videos as well. As adolescents experience symptoms of mental illness, more and more are going online to find support from possibly unhealthy sources. Looking for support 
related to self-harm is likely to lead the user to pro self-harm websites that include images and videos of self-harm as well as instructions on how to self-harm and mask self-harming behaviors (Cavazos-Rehg et al., 2017, pp. 49-50). Concerning self-harm, researchers agree that accessibility of the internet and social media have positive and negative effects. The increase of self-harm behaviors has led to an increase of peers creating suicide prevention websites where users can find resources and support (Cuen, 2015). Marchant et al., (2017) identified subjects who found emotional support and assistance with coping, but those exposed to pro self-harm content and websites were at risk of being exposed to the normalization of self-harm behavior (p. 22).

Dx: Risk for online sexual exploitation as evidence by sharing inappropriate pictures online;

Schulz et al. (2015) found simply being regularly active online leads to a risk of online sexual abuse. Victims of online sexual abuse and exploitation are likely to experience anxiety and depression. It is crucial for adolescents and children to be properly monitored online. The youth along with their care-takers need education concerning online predator awareness to combat perpetration with a victim-centered approach (p. 166).

If change is successfully enacted, nurses and social workers can begin to identify potential and current victims while also identifying risk factors to create new care plans for those at risk for injury or exploitation related to internet use. Further research into this topic also highlights problems arising with unhealthy internet use concerning amount of time spent online what some would term internet addiction (Marchant et al., 2017, pp. 15-16). Currently internet addiction has not been added to the DSM-5 due to the broad terminology, as people are addicted to activities online and not the internet in general (Zajac, Ginley, Change, \& Petry, 2017, p. 990). Studies have shown however, there is a correlation between self-harming and prolonged internet use (Marchant et al., 2017, pp. 15-16). New care plans for risks identified above are needed for the benefit and education of patients, guardians, and staff (see Table 1).

Table 1 . Internet safety care plan

\begin{tabular}{|c|c|c|c|c|}
\hline Assessment & Diagnosis & Problem & Intervention & Evaluation \\
\hline $\begin{array}{l}\text { Reports visiting websites } \\
\text { containing images of } \\
\text { self- harm }\end{array}$ & $\begin{array}{l}\text { Increased risk for } \\
\text { self-harm/self-mutilation } \\
\text { as evidenced by } \\
\text { frequently } \quad \text { visiting }\end{array}$ & $\begin{array}{l}\text { Visiting } r \text { pro } \\
\text { self-harm websites } \\
\text { may lead to an } \\
\text { increased risk of }\end{array}$ & $\begin{array}{l}\text { Online activity } \\
\text { will be better } \\
\text { monitored }\end{array}$ & $\begin{array}{l}\text { Will spend } 10 \% \\
\text { less time online } \\
\text { within one week. }\end{array}$ \\
\hline $\begin{array}{l}\text { Reports } \\
\text { visiting/participating in } \\
\text { pro self-harm } \\
\text { discussions online }\end{array}$ & $\begin{array}{l}\text { self-harm promotion } \\
\text { websites }\end{array}$ & $\begin{array}{l}\text { self-harm due to } \\
\text { normalization of } \\
\text { behavior among pro } \\
\text { self-harm } \\
\text { communities. }\end{array}$ & $\begin{array}{l}\text { Given healthy } \\
\text { online resources } \\
\text { concerning } \\
\text { topics of mental } \\
\text { health. }\end{array}$ & $\begin{array}{l}\text { Will report an } \\
\text { increase use of } \\
\text { healthy promoting } \\
\text { websites within } \\
\text { one week. }\end{array}$ \\
\hline \multicolumn{5}{|l|}{ Unrestricted time online } \\
\hline \multirow[t]{2}{*}{$\begin{array}{ll}\begin{array}{l}\text { Reports } \\
\text { cyberbullying }\end{array} & \text { frequent }\end{array}$} & & & $\begin{array}{l}\text { Given verbal } \\
\text { and written } \\
\text { education } \\
\text { concerning } \\
\text { internet safety }\end{array}$ & $\begin{array}{l}\text { Will cease use of } \\
\text { self-harm } \\
\text { promotion } \\
\text { websites within } 24 \\
\text { hours. }\end{array}$ \\
\hline & & & $\begin{array}{l}\text { Given age } \\
\text { appropriate } \\
\text { coping skills. } \\
\text { Journaling, } \\
\text { coloring, } \\
\text { drawing, writing } \\
\text { a letter to friends } \\
\text { and family } \\
\text { members }\end{array}$ & $\begin{array}{l}\text { Will report and use } \\
\text { two coping skills } \\
\text { within } 72 \text { hours. }\end{array}$ \\
\hline $\begin{array}{lcc}\text { Reports having } & \text { been } \\
\text { asked to } & \text { share } \\
\text { compromising images of }\end{array}$ & $\begin{array}{l}\text { Risk for online sexual } \\
\text { exploitation as evidence } \\
\text { by sharing inappropriate }\end{array}$ & $\begin{array}{l}\text { Unrestricted } \\
\text { internet access } \\
\text { leads to an increase } \\
\text { risk of internet }\end{array}$ & $\begin{array}{l}\text { Online activity } \\
\text { will be better } \\
\text { monitored. }\end{array}$ & $\begin{array}{l}\text { Will spend } 10 \% \\
\text { less time online } \\
\text { within one week }\end{array}$ \\
\hline
\end{tabular}




themselves online pictures online exploitation.

Reports history of sharing compromising images of themselves

Unrestricted time online

\begin{tabular}{|c|c|}
\hline $\begin{array}{l}\text { Given verbal } \\
\text { and written } \\
\text { education } \\
\text { concerning } \\
\text { internet safety. }\end{array}$ & $\begin{array}{l}\text { Will cease sending } \\
\text { compromising } \\
\text { images } \\
\text { themselves. }\end{array}$ \\
\hline $\begin{array}{l}\text { Guardians will } \\
\text { be informed of } \\
\text { potential risks to } \\
\text { minor. }\end{array}$ & $\begin{array}{l}\text { Will report three } \\
\text { negative } \\
\text { consequences } \\
\text { sharing } \\
\text { inappropriate } \\
\text { images } \\
\text { demonstrate }\end{array}$ \\
\hline $\begin{array}{l}\text { Appropriate } \\
\text { legal facilities } \\
\text { will be } \\
\text { contacted if } \\
\text { needed. }\end{array}$ & $\begin{array}{l}\text { learning within } 24 \\
\text { hours. }\end{array}$ \\
\hline
\end{tabular}

Note: Adapted from "A Systematic Review of the Relationship Between Internet Use, Self-harm and Suicidal Behavior in Young People: The good, the bad and the unknown” by A. Marchant, K. Hawton, A. Stewart, P. Montgomery, V. Singuaravelu, K. Lloyd, N. Purdy, K. Daine, and A. John, 2017, PLOS ONE, 12, p. 22.“'Online Sexual Solicitation of Minor" by A. Schulz, E. Bergen, P. Schuhmann, J. Hoyer, and P. Santtila, 2015, Journal of Research in Crime and Delinquency, 53, p. 166.

\section{Organization and Communication}

Within the target organization of change, the psychiatric units are served an emergency psychiatric triage department where mental health screenings are done to determine the level of care needed by patients in crisis. The department in total is a mixed team of 15 health care professionals comprising social workers and nurses including the unit manager who oversees the process. Disciplines involved with admissions include psychiatric providers, unit nurses, security, inpatient medical nurses, emergency room providers, nurse educators, therapy and counseling providers, and nurse managers.

As easy and cost-effective as this change may seem, one cannot bring about change without support and an established culture where communication is effective. This would not be possible without the support of the department manager. Despite the manager being simply the first layer in the hierarchy they have influence well beyond their place within the organization. Gaining support through them is essential as they are the beginning of the chain of command. Though the locus of control (Porter-O'Grady \& Malloch, 2012, p. 143) for change lies with the Director of Patient Care Services and the Executive Director of Adult Clinical Services, change must begin through the change agent's direct supervisor. If one attempted to bypass or disregard the chain it may look unfavorably upon the change agent, causing mistrust and creating resistance against action.

The organization of change has what Porter-O'Grady and Malloch (2012) would call a control design where the highest authority is at the top and power flows downward (p. 5). For all appearances, communication seems to flow easily through the branches of hierarchy, and it is easy to feel a sense of camaraderie within the upper management and administration. Communication within the organization is mostly formal between the departments but within the department communication may be more verbal and informal (see Figure 1.) 


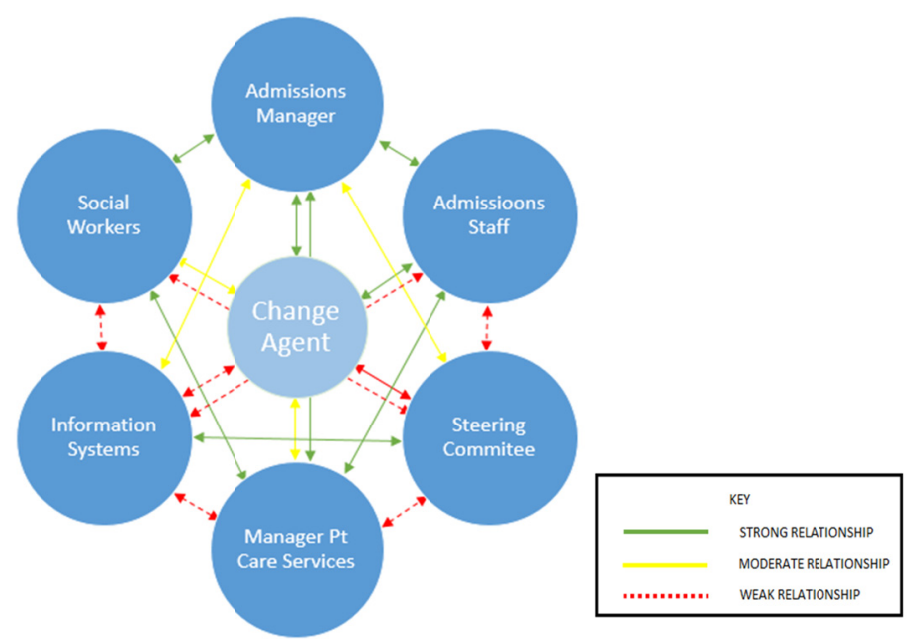

Figure 1. Lines of communication related to relationships

As stated earlier the Manager of Admissions, has great influence with upper management and daily communicates the needs of the unit. The manager's access with those higher in the hierarchy is crucial to seeking change. The change agent outside the hierarchy of management may face several barriers making it less likely to develop connections and rapport (see Figure 2). Giger (2013) states "Effective communication of health care information motivates individuals to work with their care providers to manage their health (p. 19). Additional findings, "individuals who have had effective health care communication are better informed and more confident in pursing health care." (p. 19). This line of thinking can be also applied to the manager/staff relationship. The Admissions manager's effectiveness of communication and leadership skills motivates and instills confidence in staff leading to a more cohesive environment and better patient outcomes.

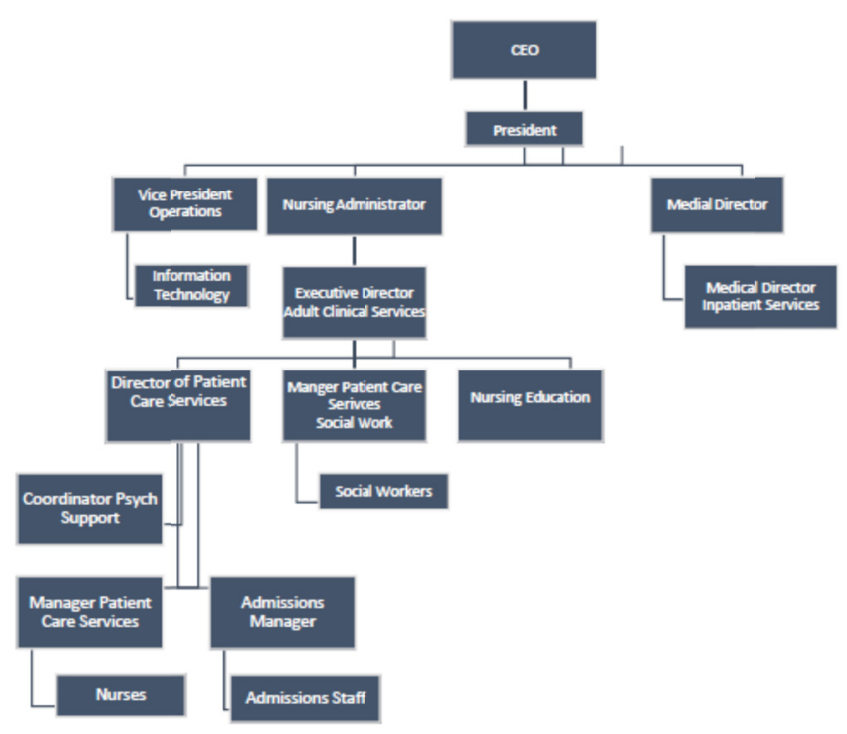

Figure 2. Organizational chart

\section{Planning for Change}

Utilizing the managers secure lines of communication will be one of the main strategies to enact change. The multiple strong lines of communication between the manager and other key players indicate a healthy environment already conducive to change. Through the strength of communication between the change agent and manager, the agent can begin by presenting detailed information on the topic including peer-reviewed 
studies highlighting the importance of change and how it can improve patient outcomes. In order to petition for more questions to be added to the screening in the electronic health record, there are several other key players who need to be involved, mainly social workers, inpatient care managers, directors and staff working in informatics (IS). Due to the small size of the organization, communication lines between these disciplines are strong except for staff within IS. Strengthening communication lines between those working in IS may be difficult due to the limited amount of time clinical staff spends in direct communication. To strengthen the communications lines between them, informatics staff must always be met with understanding and patience as they not only serve the psychiatric hospital, but the entire health system organization.

Care must also be taken when implementing change within the department specific to where change will occur. The change agent can act as servant leader and take the time to fully explain the change with goals in mind while also listening to the fears and concerns of co-workers the change will affect. This will ensure lines of communication remain strong during the period of change and help improve outcomes.

\section{Resources and Implementation}

Due to the nature of the desired change, resources needed are minimal and mainly deal with time and social capital. Though time may be minimized with prepared data and peer-reviewed resources, it is likely it will take a lengthy amount of time, anywhere between one to two months due to the workload of IS.

Preparation and organization of educational materials for teaching will be needed when presenting the change idea to the manager. It is possible the manager of admissions would require a presentation to show social workers, staff, and upper management. The presentation would ideally be prepared in PowerPoint format with handouts detailing background information and evidenced-based interventions. Once approved by the manager of admissions, and the director of patient care services it would need to be approved by the Information Steering Committee which includes the Chief Information Medical Officer and the IS Manager. The Steering Committee is a group tasked to approving forms and documentation plans within the electronic health record. For approval the manager of admissions would have to act as a sponsor and submit a form in behalf of the change agent. Once passed through the committee the task would be assigned to a systems analyst in IS who can then be involved in implementing the change within the electronic health record.

\section{Conclusion}

The entire purpose of change is to save lives, and to prevent and help people in situations who would otherwise be missed. With more research into this topic it is expected there will be an increased amount of dangerous content available online, and an increased amount of self-destructive or risky behaviors among adolescents. As technology advances, predators will continue to find new and innovative ways to find potential victims. If implemented this internet safety screening will be among the first of its kind to assess psycho-social factors and risks related to internet use. To further this goal mental healthcare workers would be presented with education related risk factors concerning internet use and adolescents and how to properly administer the screening tool to adolescent patients. For assessment of relevancy and effectiveness, every mental health screening completed must be documented on a checklist to ensure every aspect of the behavioral health screening is complete. Ideally the checklist contains three data points; Was the internet screening tool used? Did patient answer positive to high risk questions? What was the responding intervention? Possible interventions include inpatient admission, legal authorities notified, guardians notified, and education with referral given to outpatient. Success is to be measured over a thirty-day period in 3 parts; percent of adolescents screened with internet survey indicating staff participation by at least $80 \%$, At least one at risk adolescents identified, and at least $95 \%$ rate of interventions given among at risk adolescents identified.

Through careful screenings mental healthcare professionals may also be made aware of what is available online and take action to guide adolescents towards safer pathways to reduce the risk of self-destructive or risky online behaviors. The healthcare professional also serves as an educator to caregivers about the questionable content available to youth.

Porter-O'Grady and Malloch (2012) speak of how the information age has transformed the "script of life" (p. 8) Implementing change in response to new risk factors created by emerging technology is a perfect example of this line of thinking in action. As society continues to evolve, people will continue to connect and relate in new ways, changing the dynamics of social support. It is important for health professionals to continue to evaluate screening methods to better reflect the fast pace changing culture of our ever-growing digital world. 


\section{References}

Cavazos-Rehg, P. A., Krauss, M. J., Sowles, S. J., Connolly, S., Rosas, C., Bharadwaj, M., ... Bierut, L. J. (2017). An analysis of depression, self-harm, and suicidal ideation content on Tumblr. Crisis, 38(1), 44-52.

Cuen, L. (2015). Tumblr is becoming a resource for teen suicide prevention. Retrieved from http://www.vocativ.com/news/207970/tumblr-suicide/

Dorahy, M. J., \& Clearwater, K. (2012). Shame and guilt in men exposed to childhood sexual abuse: A qualitative investigation. Journal of Child Sexual Abuse, 21(2), 155-175.

Giger, J. N. (2013). Communication. Transcultural nursing: Assessment \& interventions (6th ed.), 19-31. St. Louis, MO: Elsevier/Mosby.

Marchant, A., Hawton, K., Stewart, A., Montgomery, P., Singaravelu, V., Lloyd, K., ... John, A. (2017). A systematic review of the relationship between internet use, self-harm and suicidal behavior in young people: The good, the bad and the unknown. PLOS ONE, 12(8), e0181722.

Moreno, M. A., Jelenchick, L. A., Egan, K. G., Cox, E., Young, H., Gannon, K. E., \& Becker, T. (2011). Feeling bad on Facebook: Depression disclosures by college students on a social networking site. Depression and Anxiety, 28(6), 447-455.

Nielsen Mobile Shopping Report. (2014). The U.S. Digital Consumer Report. Retrieved from http://www.nielsen.com/us/en/insights/reports/2014/the-us-digital-consumer-report.html

Porter-O'Grady, T., \& Malloch, K. (2012). Quantum leadership: Creating sustainable value in health care (5th ed.). 5-143. Boston: Jones and Bartlett.

Schulz, A., Bergen, E., Schuhmann, P., Hoyer, J., \& Santtila, P. (2015). Online sexual solicitation of minors. Journal of Research in Crime and Delinquency, 53(2), 165-188.

U.S. National Library of Medicine. (2018). Tay-Sachs disease. Retrieved from https://ghr.nlm.nih.gov/condition/tay-sachs-disease\#statistics

Zajac, K., Ginley, M. K., Chang, R., \& Petry, N. M. (2017). Treatments for internet gaming disorder and Internet addiction: A systematic review. Psychology of Addictive Behaviors, 31(8), 979-994.

\section{Copyrights}

Copyright for this article is retained by the author(s), with first publication rights granted to the journal.

This is an open-access article distributed under the terms and conditions of the Creative Commons Attribution license (http://creativecommons.org/licenses/by/4.0/). 